\title{
Measurement strategies for radon in indoor air of waterworks - a review
}

\author{
M. Stietka ${ }^{1, *}$, A. Baumgartner ${ }^{1}$, F. Kabrt ${ }^{1,2}$ and F.J. Maringer ${ }^{2}$ \\ ${ }^{1}$ BOKU, University of Natural Resources and Life Sciences, Vienna, Prueflabor fuer Umweltradioaktivitaet und Strahlenschutz, \\ Low-Level Counting Laboratory Arsenal, Arsenal 214, 1030 Vienna, Austria. \\ ${ }^{2}$ BEV, Federal Office of Metrology and Surveying, Arltgasse 35, 1160 Vienna, Austria.
}

Received: 30 March 2016 / Accepted: 1 February 2017

\begin{abstract}
In waterworks, ${ }^{222} \mathrm{Rn}$ can exhale in large amounts through open water surfaces and cause a significant dose contribution. Annual effective doses up to $56 \mathrm{mSvy}^{-1}$ are documented in literature. This paper gives a literature review on studies associated with radon measurements in indoor air of waterworks - covering more than 800 waterworks in nine regions. Special attention is given to the assessment of the workers' effective dose, which can be done either on basis of the personal exposure or on basis of the local activity concentrations and the residence times. Especially at facilities with a water treatment, large diurnal variations depending on its operation mode were reported. The average ${ }^{222} \mathrm{Rn}$ concentrations may considerably differ during the time spent of the staff and do not allow to determine the correct annual effective doses. Personal detectors avoid this problem and do not require the survey of the residence times, while the determination of the local exposure allows for the identification of spots with high activity concentrations to set dose reduction measures.
\end{abstract}

Keywords: indoor radon / water treatment / NORM / workplace

\section{Introduction}

Many epidemiologic studies prove that indoor radon exposure is responsible for a substantial number of lung cancers in the general population (Darby et al., 2005). After cigarette smoking, radon is the most frequent cause of lung cancer. Regarding radiation protection, the most important isotope of radon is ${ }^{222} \mathrm{Rn}$, and in Austria, the inhalation of indoor radon contributes with about $54 \%$ to the annual effective dose of the population (Maringer et al., 2012). Following the ICRP recommendations, current dose conversion factors for the inhalation of radon daughters, which are derived from epidemiologic studies, will be revised. It is likely that the result will be an increase in effective dose per unit exposure of around a factor of two (ICRP, 2009). Dosimetric evaluations of the absorbed dose to basal cells of the bronchial epithelium provide a conversion factor 2.5 times higher than the epidemiologic approach (UNSCEAR, 2008).

Since 2013, a revised Basic Safety Standards Directive (Council Directive 2013/59/Euratom, 2013) lays down basic safety standards for protection against the dangers arising from exposure to ionising radiation. This Directive shall be brought into national law of the member states by 2018 . The updated Directive covers the whole range of radiation sources and

\footnotetext{
* Corresponding author: michael.stietka@boku.ac.at
}

categories of exposure including occupational, medical, public and environmental exposure. One special focus is on the protection of workers in workplaces with indoor ${ }^{222} \mathrm{Rn}$ and in activities processing Naturally Occurring Radioactive Materials (NORM).

Industrial activities can lead to an enhanced exposure to NORM in products, by-products, residues and wastes. There are specific working areas, in which elevated ${ }^{222} \mathrm{Rn}$ activity concentrations can occur. Waterworks are part of these areas (BMLFUW, 2008). ${ }^{222} \mathrm{Rn}$ can escape from the ground and is dissolved in ground water. In waterworks, it can be outgassing in large amounts due to open water surfaces and high water flow rates.

In order to perform traceable, accurate, standardised measurements, improved measurement practices and procedures are required for NORM industries. The standards for ${ }^{222} \mathrm{Rn}$ determination of indoor air are mainly designed for dwellings, in which different conditions regarding the influence on the ${ }^{222} \mathrm{Rn}$ activity concentration are predominant. A detailed literature study is the first step to develop improved measurement practices for specific working areas like waterworks. The main objectives of this review are to compare and discuss different studies focussed on ${ }^{222} \mathrm{Rn}$ in indoor air of waterworks from the aspect of the presented results as well as the applied methodology of the ${ }^{222} \mathrm{Rn}$ measurements. Special emphasis is given to the annual effective dose of the workers. Besides, strategies for waterworks testing are compiled from literature. 


\section{Overview - radon in waterworks}

Generally, the ${ }^{222} \mathrm{Rn}$ activity concentrations in water tank facilities and other parts of waterworks, such as the water treatment or fountains, can be much higher than in common domestic buildings (Nagels et al., 2009). The main source of ${ }^{222} \mathrm{Rn}$ emanation within a waterworks is the water itself. Though potable water can be a source of ${ }^{222} \mathrm{Rn}$ in indoor air of dwellings (Nazaroff et al., 1987), it is much more important in waterworks. ${ }^{222} \mathrm{Rn}$ can outgas from the water into indoor air of waterworks and can cause a significant contribution to the annual effective dose of the waterworks staff (Tab. 1).

Many factors have an impact on the ${ }^{222} \mathrm{Rn}$ activity concentration in the water, such as the pathways of the aquifers. The mineralogical composition of the aquifer and the permeability of soil affect the ${ }^{222} \mathrm{Rn}$ activity concentration in water (Loomis, 1987; Trautmannsheimer et al., 2003). Rock types differ in the uranium concentration and therefore in the radium concentration, which influences the ${ }^{222} \mathrm{Rn}$ activity concentration in soil gas and ground water. Relevant parameters for the exhalation rate of ${ }^{222} \mathrm{Rn}$ in water into the indoor air of waterworks are the water flow rate and the type of water input (Hingmann et al., 2001). Besides the exhalation rate, the ventilation heavily influences the ${ }^{222} \mathrm{Rn}$ activity concentration in indoor air of waterworks. For that reasons an assessment of ${ }^{222} \mathrm{Rn}$ in air on basis of ${ }^{222} \mathrm{Rn}$ in water is not reasonable (Stietka et al., 2014).

The facilities of a waterworks differ in terms of size and structure. High ${ }^{222} \mathrm{Rn}$ activity concentrations tend to occur at those parts of a waterworks with high water flow rates and a small air volumes, e.g. the tapping of a spring. The farther a facility is located from the spring the more ${ }^{222} \mathrm{Rn}$ could already have been outgassed or decayed. Like in dwellings, the ${ }^{222} \mathrm{Rn}$ activity concentrations in waterworks are subject to diurnal and seasonal variations, also tending to higher concentrations in the cold season (Stietka et al., 2013).

Overall, there are rare publications in the field of radon in waterworks, therefore some statements, which are applicable to radon in waterworks, are related to radon in indoor air in general.

\subsection{Measurement aspects}

Generally, for the monitoring of radon, both active and passive techniques exist. Passive methods require a preparation and an evaluation process, whereas the results are instantaneously available with active devices. In waterworks, the latter ones are mainly used for short-term measurements serving as an overview and for detailed investigations of individual sites. According to the WHO (2009), short-term refers to measurements that average radon concentrations over days or weeks, while long-term measurements generally cover a season or more (several months to one year). Due to temporal variations of the ${ }^{222} \mathrm{Rn}$ activity concentration in waterworks, short-term measurements are not suitable as basis for dose assessments (Stietka et al., 2013). To provide a realistic exposure scenario, long-term measurements at various measurement points are necessary for the most waterworks. For such simultaneous long-term measurements at numerous sites, passive devices offer advantages because of their moderate costs.

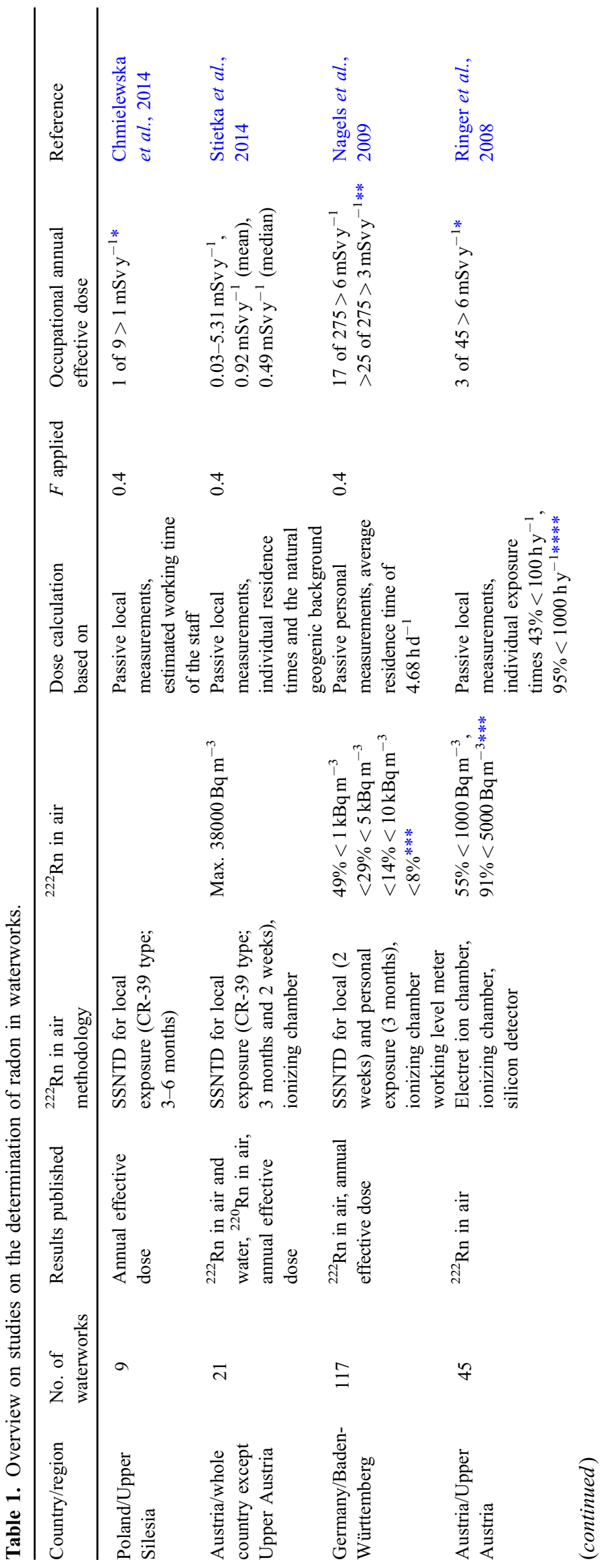




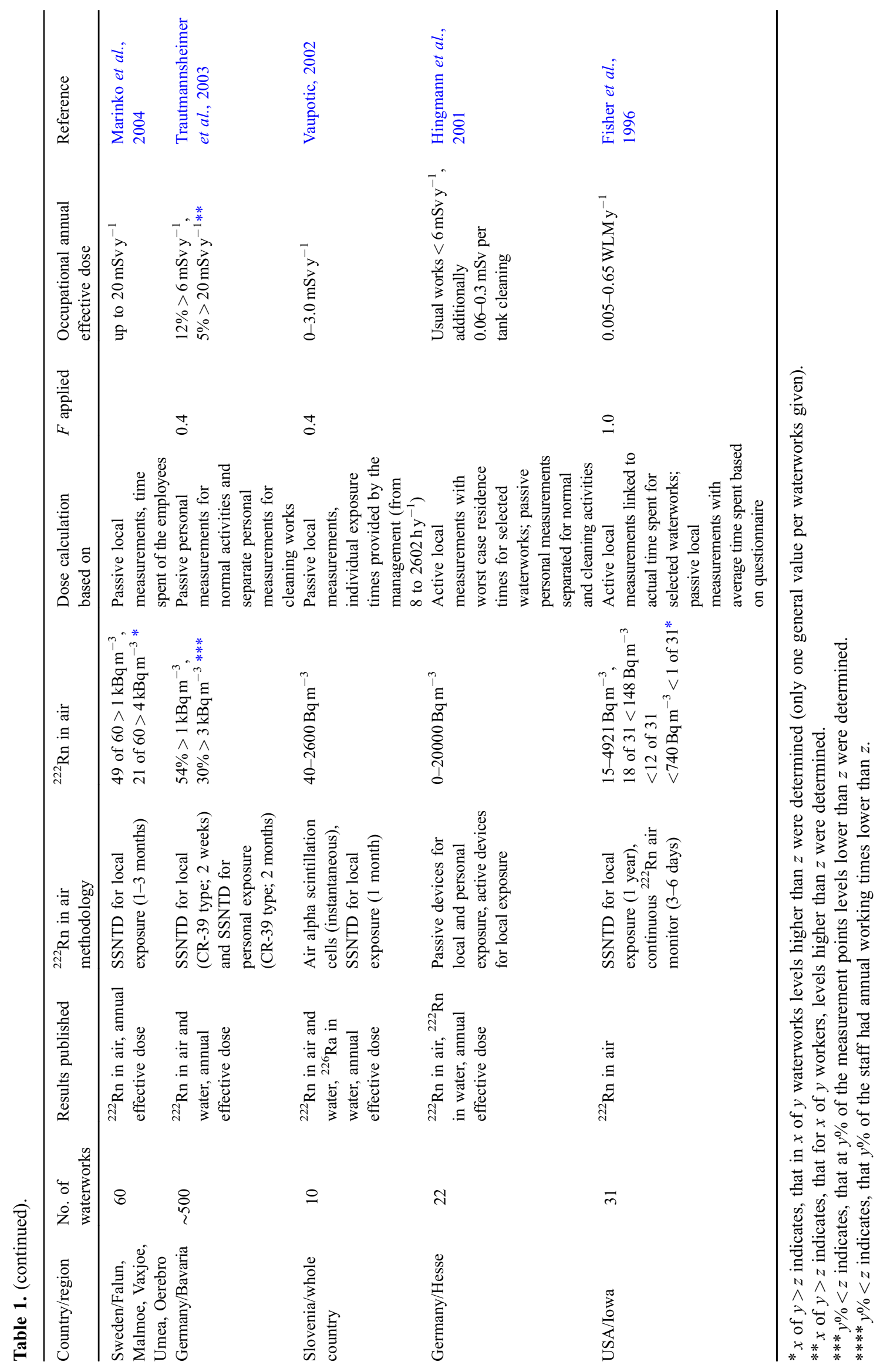


For long-term indoor radon measurements in general, solid-state nuclear track detectors or SSNTDs are a reliable, sufficient and inexpensive passive measurement technique (Ahn and Lee, 2005; Banjanac et al., 2006). The alpha particles leave nuclear tracks at the detection films of the SSTNDs, which can be evaluated after etching, usually with $\mathrm{NaOH}$. The most popular of these detector types are based on CR-39 polycarbonate films, because of its good sensitivity, stability against various environmental factors, and high degree of optical clarity. CR-39 films inside a closed detector cup are not as sensitive to humidity and dust effects as other methods (Nikezic and Yu, 2000). With closed detector cups, ${ }^{222} \mathrm{Rn}$ diffuses through the encapsulation into the measuring chamber, whereas the ${ }^{222} \mathrm{Rn}$ decay products, dust and moisture are blocked. This is an important factor for ${ }^{222} \mathrm{Rn}$ measurements in waterworks. On the other hand, open cupped detectors, frequently on basis of LR 115 nitrate cellulose films, are sensitive to the alpha particles of ${ }^{222} \mathrm{Rn}$ and ${ }^{220} \mathrm{Rn}$ as well as their progenies. ${ }^{220} \mathrm{Rn}$ (the so-called thoron) with a half-life of $56 \mathrm{~s}$ can rarely occur in waterworks, see chapter 2.2. Special double detectors with a closed and an open cup allow for a ${ }^{222} \mathrm{Rn} /{ }^{220} \mathrm{Rn}$ discrimination (Tokonami et al., 2005).

In contrast to passive methods, active devices require a battery pack or power supply, which is not available in every part of a waterworks. The most popular active techniques applied for monitoring are ionization chambers and solidstate silicon detectors. The latter ones have small-dimension diffusion chambers. Therefore, long integration times are essential to reach a statistically stable value, whereas ionization chambers having generally larger measurement chambers can fulfil the requirements for quick overview measurements in waterworks. There also exist active devices for the determination of ${ }^{220} \mathrm{Rn},{ }^{220} \mathrm{Rn}$ progenies as well as ${ }^{222} \mathrm{Rn}$ progenies.

Considering their operating humidity, some devices or measurement methods are not suitable for the application in waterworks in general.

\subsection{Dose aspects}

Though the inhalation of short-lived ${ }^{222} \mathrm{Rn}$ progeny and not ${ }^{222} \mathrm{Rn}$ itself is dose relevant, determining the ${ }^{222} \mathrm{Rn}$ activity concentration is a common, more convenient practice. For dose assessment on basis of the ${ }^{222} \mathrm{Rn}$ activity concentration, the consideration of the equilibrium factor is essential. The equilibrium factor characterizes the disequilibrium between the mixture of the short-lived progeny and their parent nuclide, radon, in air in terms of potential alpha energy (ICRP, 1993). UNSCEAR (1988) and the ICRP (1993) have adopted a typical worldwide equilibrium factor of 0.4 for ${ }^{222} \mathrm{Rn}$ in indoor air. In situations where the equilibrium factor differs significantly from the usually assumed value of 0.4 , a direct determination of the ${ }^{222} \mathrm{Rn}$ decay products can be performed (WHO, 2009). Within surveys in Upper Austria, Bavaria, Hesse and BadenWuerttemberg mean values of $0.52,0.5,0.37$ and 0.55 for the equilibrium factor of indoor air of waterworks were found (AGES, 2006). Out of Table 1 and the values above, it can be seen that there is no clear indication to use another value for waterworks than the generally recommended indoor value of 0.4 (UNSCEAR, 1988; ICRP, 1993). There is only a very limited amount of data published on the equilibrium factor determined in the indoor air of waterworks.

Besides the equilibrium factor, other influence factors on the dose conversion such as the distribution of aerosol diameters and the unattached fraction (Yu and Nikezic, 2012) may differ from those in dwellings. No publication was found, which addresses these parameters for waterworks.

The short-lived ${ }^{220} \mathrm{Rn}$ can occur in some parts of waterworks. Dosimetric evaluations in UNSEAR (2008) give dose coefficients in the range of $6-15 \mathrm{nSv}\left(\mathrm{Bq} \mathrm{h} \mathrm{m}^{-3}\right)^{-1}$ for ${ }^{222} \mathrm{Rn}$ and $40 \mathrm{nSv}\left(\mathrm{Bq} \mathrm{h} \mathrm{m}^{-3}\right){ }^{-1}$ for ${ }^{220} \mathrm{Rn}$ (for equilibrium equivalent concentrations). Within a Bavarian survey of Trautmannsheimer (2002), ${ }^{220} \mathrm{Rn}$, exhaling from the water, was found within a water chamber of a waterworks. Due to its short half-life, the activity concentration of ${ }^{220} \mathrm{Rn}$ was much lower in the other parts of the same building. In this study, it was found out that the ${ }^{220} \mathrm{Rn}$ caused dose is no higher than $10 \%$ of the dose of the ${ }^{222} \mathrm{Rn}$ decay products. In Stietka et al. (2014), ${ }^{220} \mathrm{Rn}$ was detected in 3 out of 47 measurements. In an Upper Austrian study (AGES, 2006), where ${ }^{220} \mathrm{Rn}$ was investigated in five waterworks, no ${ }^{220} \mathrm{Rn}$ was found at all.

Table 1 summarizes the results of the literature survey and gives an overview on studies with the focus on the determination of radon in waterworks. For each study only the most comprehensive or relevant publication was mentioned in Table 1, so the shown results rely on different datasets. Also very specific studies or small ones, based on measurements in a small number of participating waterworks (e.g. Aakerblom et al., 2002), were excluded because of lack of representativeness. As far as possible, the results were presented in their original form to avoid a bias of the outcomes. Besides the values for the ${ }^{222} \mathrm{Rn}$ activity concentration in indoor air of waterworks, other results and relevant information are presented, which are the used methodology for the determination of ${ }^{222} \mathrm{Rn}$ in air, the activity concentrations of ${ }^{222} \mathrm{Rn}$ in water, the equilibrium factor $F$ applied for dose calculation, and the annual effective dose of the staff. The maximum values reported in these studies were more than $50000 \mathrm{~Bq} \mathrm{~m}^{-3}$ (Marinko et al., 2004) for ${ }^{222} \mathrm{Rn}$ in air, $1200 \mathrm{~Bq} \mathrm{I}^{-1}$ (Trautmannsheimer et al., 2003) for ${ }^{222} \mathrm{Rn}$ in water and $56 \mathrm{mSv} \mathrm{y}^{-1}$ (Ringer et al., 2008) for the annual effective dose of the waterworks staff.

\section{Strategies for waterworks testing}

\subsection{Methodology}

As it can be seen in Table 1 , the results of the ${ }^{222} \mathrm{Rn}$ measurements of indoor air in waterworks mostly serve as basis for dose assessment. The calculation of the effective dose can be done either on basis of the personal exposure (e.g. Trautmannsheimer et al., 2003; Nagels et al., 2009) or on basis of the local activity concentrations and the residence times (e.g. Fisher et al., 1996; Vaupotic, 2002; Marinko et al., 2004; Chmielewska et al., 2014; Stietka et al., 2014). Regarding possible, subsequent dose reduction measures, a determination of the local activity concentration is needed. In case of future changes in the residence times at specific locations, this method is also favourable. The effective dose can simply be recalculated out of the representative activity concentrations and no new measurements are required. 
When collecting the data about the residence times of the affected employees, special attention should be paid to the exposure during cleaning works or repair works at facilities with open water surfaces. During these activities, a different ${ }^{222} \mathrm{Rn}$ concentration can occur (Hingmann et al., 2001).

At facilities with a water treatment, there can be large diurnal variations depending on its operation mode, e.g. ${ }^{222} \mathrm{Rn}$ can outgas in large amounts during the backwash process of a filter (Fisher et al., 1996). In some of these cases, it is expedient to consider these diurnal variations of the activity concentration with separate measurements. These should be conducted with an active measurement device with a sufficient time resolution (Hingmann et al., 2001). Except for some above mentioned selected measurement points in the studies of Fisher et al. (1996) and Hingmann et al. (2001) all annual effective doses reported in Table 1 are based on passive measurements without time resolution. Both studies show, that the average ${ }^{222} \mathrm{Rn}$ concentrations may significantly differ from those during the residence times of the staff. In these cases the average ${ }^{222} \mathrm{Rn}$ concentrations do not allow to determine the correct annual effective doses.

For water purification buildings, the radon concentrations are much higher in case of the presence of the process controller than the average concentration (Trautmannsheimer et al., 2003). Considering this problem and the insufficient availability of the exact time spent in the water supply facilities, Trautmannsheimer et al. (2003) sees personal detectors as the most reliable method to evaluate the radon exposure of the staff. In his study, he conducted $\sim 3000{ }^{222} \mathrm{Rn}$ long-term measurements. Usually the lack of sufficient equipment does not allow the general use of active ${ }^{222} \mathrm{Rn}$ measurement devices with time resolution.

On the other hand, Hingmann et al. (2001) reported problems with the handling and regular wearing of the personal detectors. In addition, personal ${ }^{222} \mathrm{Rn}$ detectors do not allow identifying the locations with high activity concentrations to set dose reduction measures. Nagels et al. (2009) pointed out, that effective doses for workers of external companies could be calculated on basis of the local ${ }^{222} \mathrm{Rn}$ concentrations.

\subsection{Equipment and determination of the radon activity concentration}

During visits at waterworks, it could be helpful to start with active measurements (as conducted by Fisher et al., 1996; Hingmann et al., 2001; Vaupotic, 2002; Ringer et al., 2008; Nagels et al., 2009; Stietka et al., 2014). Such short-term measurements - preferably conducted with a high-efficiency active device with a display operated in flow mode (e.g. an ionization chamber) - can give a quick overview about the situation. Works in the course of the measurements can reduce the present activity concentration by ventilation effects or low water flow rates. Keeping the ventilation and operation conditions in the usual state during the measurements can prevent this and ensures representative results. This is especially important for short-term measurements.

Out of the active short-term measurements, one can decide to shorten the measurement time of the passive long-term measurements or to split it up to prevent overexposure, in case of high ${ }^{222} \mathrm{Rn}$ activity concentrations. Overexposure causes high track densities on the detector film, which can make the evaluation impossible. Further, the results of the active devices can help to speed up for prompt remediation measures. In order to obtain more reliable values for rapid technical remediation measures, it can be helpful to conduct passive short-term measurements.

For ${ }^{222} \mathrm{Rn}$ measurements in indoor air in general, passive SSNTDs have a well-documented history of application (Tommasino, 2001). For the determination of the annual effective dose caused by ${ }^{222} \mathrm{Rn}$ in waterworks, the literature listed in Table 1 shows, that passive long-term measurements with SSNTDs are a reasonable choice. The closer the measurement time is to one year, the more representative it will be of annual average radon levels.

As can be seen in Table 1, the determination of the local ${ }^{222} \mathrm{Rn}$ activity concentration is the mainly used method, whereas in the studies of Nagels et al. (2009) and Trautmannsheimer et al. (2003), the dose calculations were based on the personal ${ }^{222} \mathrm{Rn}$ exposures.

Normally, installing one detector in every room where persons stay is adequate for the determination of the local exposure. Within rooms with large air spaces, the radon activity concentration can vary considerably. In this case, several detectors within one room provide a more realistic exposure scenario.

For ${ }^{222} \mathrm{Rn}$ in indoor air in general, an optimal height for positioning the detector is the breathing zone (EPA, 1993). A position should be selected, where the detector will not be disturbed during the measurement period or disturbs the ongoing works of the waterworks staff. For waterworks, especially in the field of drinking water production, hygiene is very important issue, which has to be considered e.g. for positioning the measurement devices. In addition, measurements should not be conducted near drafts caused heating or vents (EPA, 1993).

For the proof of effectivity of the set dose reduction measures, it is necessary to repeat the measurements after a remediation process (e.g. Ringer, 2008). In case of high annual effective doses, the repeat of measurement after remediation is enshrined in the national act or ordinance, e.g. BMLFUW (2008).

Additionally to the ${ }^{222} \mathrm{Rn}$ measurement devices, a dose rate meter is frequently used as a supplementary instrument in waterworks (Ringer et al., 2008). It can help to identify water filters enriched with ${ }^{226} \mathrm{Ra}$, which could be a source of ${ }^{222} \mathrm{Rn}$ emanation. Besides, the filter materials as well as the residues from the backwash process can contain several other, natural radionuclides (Fonollosa et al., 2015).

\subsection{Evaluation of measurement results}

If the measurements are intended to provide a representative annual-average radon concentration, there are some general considerations. These should be given to measurement variability and the predictive value of the results, given the uncertainties that arise from spatial, temporal and instrument variations (WHO, 2009). Especially for waterworks, temporal variations depending on the operation mode of the water treatment have been documented in Fisher et al. (1996) and seasonal variations in Stietka et al. (2013).

Concerning seasonal variations for radon in indoor air in general, depending on the country, there are different 
circumstances and approaches to handle this problem. In some countries, measurements made in various seasons are adjusted to estimate an annual-average ${ }^{222} \mathrm{Rn}$ concentration based on "typical" seasonal variations (Baysson et al., 2003). For measurements of a few months, the WHO (2010) suggests, that a seasonal adjustment factor, if available, may be applied to obtain an estimate of the annual average value. In Austria, these factors have been defined especially for waterworks, which include a correction for the ${ }^{222} \mathrm{Rn}$ activity concentration, depending on the season, as well as for its uncertainty depending on the measurement duration (Stietka et al., 2014).

To evaluate the measured ${ }^{222} \mathrm{Rn}$ exposures with regard to the effective dose of the waterworks staff, usually an equilibrium factor of 0.4 is applied, as can be seen in Table 1 . The applied equilibrium factor of 1.0 in Fisher et al. (1996) was declared as conservative basis for the calculation of the working-level month.

\section{Conclusion}

This literature review on studies directly associated with ${ }^{222} \mathrm{Rn}$ measurements in waterworks, covering more than 800 waterworks in nine regions, shows that ${ }^{222} \mathrm{Rn}$ can exhale in large amounts through open water surfaces in this working area and cause a significant dose contribution for the staff. For the ${ }^{222} \mathrm{Rn}$ activity concentration in indoor air of waterworks, values higher than $50000 \mathrm{~Bq} \mathrm{~m}^{-3}$ were documented in the literature (Marinko et al., 2004) and annual effective doses as high as $56 \mathrm{mSvy}^{-1}$ were reported (Ringer et al., 2008).

In this study, measurement strategies for ${ }^{222} \mathrm{Rn}$ in waterworks were collected and analysed. The results of ${ }^{222} \mathrm{Rn}$ measurements in indoor air of waterworks mostly serve as basis for dose assessment. The assessment of the workers' effective dose can be done either on basis of the personal exposure or on basis of the local activity concentrations and the residence times. The determination of the local exposure allows for the identification of spots with high activity concentrations to set dose reduction measures.

Personal detectors do not require the survey of the residence times at specific locations and therefore avoid problems caused by variations of the ${ }^{222} \mathrm{Rn}$ activity concentration. Especially at facilities with a water treatment, large diurnal variations depending on its operation mode were reported. Also during cleaning or repair works, different ${ }^{222} \mathrm{Rn}$ concentrations can occur. The average ${ }^{222} \mathrm{Rn}$ concentrations may considerably differ from those during the time spent of the staff and do not allow to determine the correct annual effective doses.

For the calculation of the annual effect dose, there is no clear indication in literature to use another equilibrium factor for waterworks than the generally recommended indoor value of 0.4. Overall, there are rare publications in the field of radon in waterworks. More investigation is needed, especially regarding ${ }^{220} \mathrm{Rn}$, and influence factors on the dose conversion, e.g. the equilibrium factor, the distribution of aerosol diameters and the unattached fraction.

Acknowledgements. This work was done within the Joint Research Project IND57 MetroNORM in the framework of the European Metrology Research Programme (EMRP). MetroNORM is aimed to develop improved methods for laboratory and in situ measurements and to design standardised procedures, as well as perform testing in industrial environment. The EMRP is jointly funded by the EMRP participating countries within EURAMET and the European Union.

\section{References}

Aakerblom G, Hagberg N, Mjoenes L, Heiberg A. 2002. High indoor radon concentrations in some Swedish waterworks. In: Natural ionizing radiation and health, June 6-7, 2001, Oslo, pp. 45-54. Norwegian Academy of Science and Letters, Trondheim.

AGES - Austrian Agency for Health and Food Safety. 2006. Strahlenexposition von Beschaeftigten in oberoesterreichischen Wasserwerken. AGES, Linz.

Ahn GH, Lee JK. 2005. Construction of an environmental radon monitoring system using CR-39 nuclear track detectors. NET37: 395-400.

Banjanac R, Dragic A, Grabez B, Jokovic D, Markushev D, Panic B, Udovicic V, Anicin I. 2006. Indoor radon measurements by nuclear track detectors: applications in secondary school. $F U$ Phys. Chem. Tech. 4: 93-100.

Baysson H, Billion S, Laurier D, Rogel A, Tirmarche M. 2003. Seasonal correction factors for estimating radon exposure in dwellings in France. Radiat. Prot. Dosim. 104: 245-252.

BMLFUW - Austrian Federal Ministry of Agriculture and Forestry, Environment and Water Management. 2008. Natuerliche Strahlenquellen-Verordnung, BGB1. II 2/2008. BMLFUW, Vienna.

Chmielewska I, Chałupnik S, Bonczyk M. 2014. Natural radioactivity in drinking underground waters in Upper Silesia and solid wastes produced during treatment. Appl. Radiat. Isot. 93: 96-100.

Council Directive 2013/59/Euratom of 5 December 2013 laying down basic safety standards for protection against the dangers arising from exposure to ionising radiation. Off. J. L. 13: 1-73.

Darby S, et al. 2005. Radon in homes and risk of lung cancer: collaborative analysis of individual data from 13 European casecontrol studies. BMJ 330: 223-330.

EPA. 1993. Protocols for radon and radon decay product measurements in homes. EPA 402-R-92-003, Washington, DC.

Fisher EL, Fuortes LJ, Field RW. 1996. Occupational exposure of water-plant operators to high concentrations of radon-222 gas. J. Occup. Env. Med. 38: 759-764.

Fonollosa E, Nieto A, Penalver A, Aguilar C, Borrull F. 2015 Presence of radionuclides in sludge from conventional drinking water treatment plants. A review. J. Environ. Rad. 141: 24-31.

Hingmann H, Ehert V, Heinricht W, Weber J, Hegenbart L. 2001. Radon in hessischen Wasserwerken - Einflussgroessen und Exposition der Beschaeftigten. In: Mueck K, Hefner A, Vana N (Eds.), Strahlenschutz fuer Mensch und Gesellschaft im Europa von Morgen. TUEV-Verlag, Koeln, pp. 182-185.

ICRP Publication 65. 1993. Protection Against Radon-222 at Home and at work. Ann. ICRP 23 (2).

ICRP. 2009. Statement on Radon.

Loomis DP. 1987. The relationship between water-system size and Rn-222 concentration in North Carolina public water supplies. Health Phys. 52: 69-71.

Maringer FJ, Seidel C, Preinerstorfer A, Baumgartner A, Rechberger F, Schuff M, Stietka M. 2012. Ermittlung der aktuellen Haeufigkeitsverteilung der natuerlichen Strahlenexposition der oesterreichischen Bevoelkerung. University of Natural Resources and Life Science, Vienna.

Marinko J, Mjoenes L, Soederman A-L. 2004. Radon measurements in air in waterworks and indoor swimming pools - a primary mapping project. In: 4th European conference on protection against radon at home and at work, June 28-July 2, 2004, Prague, Book of abstracts, p. 56. 
Nagels S, Ugi S, Urban M. 2009. Radonerhebungsmessungen in Wasserwerken in Baden-Wuerttemberg. Karlsruhe Institute of Technology, Karlsruhe.

Nazaroff WW, Doyle SM, Nero AV, Sextro RG. 1987. Potable water as a source of airborne Rn-222 in U.S. dwellings: a review and assessment. Health Phys. 52: 281-295.

Nikezic D, Yu KN. 2000. Uncertainty in radon measurements with CR39 detector due to unknown deposition of Po-218. Nucl. Instr. Meth. A 450: 568-572.

Ringer W, Simader M, Bernreiter M, Kaineder H. 2008. Mitigation of three water supplies with high radon exposure to the employees. Radiat. Prot. Dosim. 130: 26-29.

Stietka M, Baumgartner A, Seidel C, Maringer FJ. 2013. Development of standard methods for activity measurement of natural radionuclides in waterworks as basis for dose and risk assessment - first results of an Austrian study. Appl. Radiat. Isot. 81: 279-283.

Stietka M, Baumgartner A, Seidel C, Rechberger F, Ringer W, Maringer FJ. 2014. Radon in waterworks: dose assessment, analysis of influence parameters and improved methods of measurement. Radiat. Prot. Dosim. 160: 138-142.

Trautmannsheimer M. 2002. Radonexponierte Arbeitsplaetze in Wasserwerken in Bayern. Bavarian Land Office for Environment, Augsburg.
Trautmannsheimer M, Schindlmeier W, Börner K. 2003. Radon concentration measurements and personnel exposure levels in Bavarian water supply facilities. Health Phys. 84: 100-110.

Tokonami S, Takahashi H, Kobayashi Y, Weihai Z, Hulber E. 2005. Up-to-date radon-thoron discriminative detector for a large scale survey. Rev. Sci. Instrum. 76: 3505-3509.

Tommasino L. 2001. Personal dosimetry and area monitoring for neutrons and radon in workplaces. Radiat. Meas. 34: 449-456.

UNSCEAR. 1988. United Nations Scientific Committee on the Effects of Atomic Radiation, Sources, effects and risks of ionizing radiation. Report to the general assembly with annexes, United Nations, New York.

UNSCEAR. 2008. United Nations Scientific Committee on the Effects of Atomic Radiation, Sources and effects of ionizing radiation. Report to the general assembly with scientific annexes. United Nations, New York.

Vaupotic J. 2002. Radon exposure at drinking water supply plants in Slovenia. Health Phys. 83: 901-906.

WHO. 2009. WHO handbook on indoor radon: a public health perspective.

WHO. 2010. WHO guidelines for indoor air quality: selected pollutants.

Yu KN, Nikezic D. 2012. Long-term measurements of unattached radon progeny concentrations using solid-state nuclear track detectors. Appl. Radiat. Isot. 70: 1104-1106.

Cite this article as: Stietka M, Baumgartner A, Kabrt F, Maringer FJ. 2017. Measurement strategies for radon in indoor air of waterworks - a review. Radioprotection 52(2): 101-107 